tion in that they show that a difference in methods of experimentation and in the treatment of material will bring about definite and predictable differences in the results reached; and that they thus emphasize the value and reliability of the statistical method, when efficiently applied, in the study of mental phenomena.

Madison, Wis., October $34,1895 .^{1}$

JOSEPH JASTROW.

\title{
THE FUNCTIONS OF THE RODS OF THE RETINA.
}

v. Kries has written a long article (Zeitschr. f. Psych., IX., 8I123) in which he sets forth the reasons for considering that the rods are the seat of the faint-light sensation (which is the name by which I have designated the sensation of gray which remains after colors are no longer distinguishable), of the peripheral sensation, and of the sensation of the totally color-blind. His argument is extremely effective, and ought to carry conviction to every one who studies it thoroughly. I confess that I am somewhat surprised at his constantly referring to this idea as his hypothesis, and as the 'just developed' hypothesis. I had supposed that it was a fundamental part of my theory of light-sensation; and I am the more surprised at this because v. Kries expressly says in one place: "It may here be mentioned that the assumption according to which the rods are capable only of the production of the colorless sensation is found in the theory which has been developed by Chr. Ladd-Franklin." Apparently it is because he is unable to adopt my theory (nor even to understand it, he says) that he considers it proper to ignore the fact that the hypothesis in regard to the function of the rods is not now put forward, with any strong evidence in its favor, for the first time. (Max Schultze already in 1866 suggested this as the function of the rods, on the ground that many night-seeing animals have rods only, or chiefly, in the retina.)

As regards v. Kries' criticism of my theory, I have two remarks to make. In the first place, the assumption which he considers so objectionable a feature, and which he finds it impossible to form any conception of-the assumption, namely, "that the atoms of the outer layer have become separated into three groups at right angles to each other," is not an essential part of the theory-is, in fact, merely a mode of expression adopted for the purpose of giving the molecules

${ }^{1}$ I must explain that the delay in the appearance of the above rejoinder is due to a long illness and resulting accumulations of duties. 
conceived of a certain degree of symmetry. All that is essential in the idea is that a photochemical substance which in the rods goes to pieces all at once under the influence of light of any kind has been so modified in the cones that it can go to pieces in three different stages, under the influence respectively of three different groups of wavelength. Merely to give a resting-place to the imagination, I make a diagrammatic representation of two molecules, of a just sufficient degree of complexity to answer this purpose, in this way, for instance:
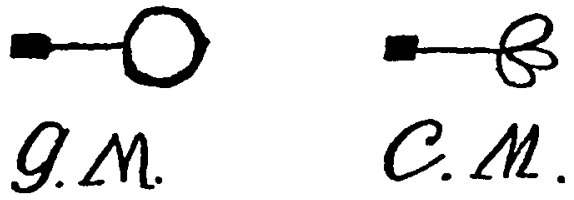

The real molecules (if such exist) are, of course, of very different appearance from this, and of immensely greater complexity. My hypothesis that the vibrations which are going on in the outer portions of the molecule are so timed as to cause the molecule to be disintegrated by ether vibrations of the velocity of the visible portion of the spectrum, but not by those which are either more rapid or less rapid, is at the same time an hypothesis to account for selective chemical dissociation in organic substances in general. It is far from being remote from current physiological or chemical speculation. Jensen, in a late number of Pfinger's Archiv (LXII., I 72-20I) makes use of it to account for the extraordinary fact that, in animals so low down as the foraminifera, a state of contractory excitation is caused by the cut off pseudopodia of a different individual, while the pseudopodia of the same individual, though cut off in exactly the same way, produce no effect whatever; he makes the suggestion, since no morphological ground can be assigned for this difference, that an explanation must be sought in the idea, first made use of by Pflüger in his memorable paper of 1875 , that every portion of living matter is a system of countless little differently tuned harps, and that non-synchronously vibrating portions of protoplasm act destructively upon one another when brought into contiguity. The origin of the idea in my own mind dates from the reading of a paper by Ebbinghaus.

My second remark is this: The very difficulty which my theory was gotten up to meet (given a separate grey process and complementary, not antagonistic, colors) has not apparently occurred to $\mathbf{v}$. Kries as being a difficulty at all, and hence it is not surprising that he does not feel the necessity for my assumption. He says that in lay- 
ing down a definite relation between the monochromatic and the trichromatic elements, I give up the advantage which should be gained by separating them. But is there not a tremendously definite relation between the sensations in question? The grey sensation due to the decomposition in the rods is absolutely indistinguishable in quality from the grey sensation due to the decomposition in the cones. What could be more natural then-more indispensable in fact-than to give this remarkable resemblance a physical basis in the theory? Nor can I see that anything whatever is lost by so doing. Far from my not having 'remarked' the connection between my assumptions and the Purkinje phenomenon, I had already suggested an explanation of that phenomenon in my paper in Mind, Vol. III., N. S., p. 103 (which v. Kries seems to have overlooked) and have since pointed out the inevitableness of this explanation in the light of the more recently added facts.

Prof. v. Kries attributes importance to the observation of Ebbinghaus and myself that a grey made of red and green is a very different thing from a grey made of blue and yellow, and considers that Hering himself must admit that it is thoroughly destructive of his theory, so soon as Hering shall have convinced himself of the correctness of the observation. v. Kries himself finds it extremely easy of confirmation.

\section{Ladd Frankilin.}

\section{SOMETHING MORE ABOUT THE 'PROSPECTIVE REFERENCE' OF MIND.}

In the last number of this Review (November, I895), Prof. Baldwin handled the problem of the completeness and satisfactoriness of the purely scientific answer as to the nature of the functions of knowledge. After showing the impossibility inherent in the very nature of the scientific historical categories of their saying the last word about any organized developing real, he applies the argument, a fortiori, to those developing reals which we call the functions of consciousness. Any thing of organization is only known by its activities, and my present conception of it is of the sum of its known activities up to the present moment. This is the scientific or historical view of a thing, or to use Prof. Baldwin's term, the 'retrospective reference' of mind. Under this view we can determine the 'how, the manner of the development of a given thing; but does this give us the right to consider its past history the whole reality, the 'what' of the object of our study? Assuredly not, for we are 